\title{
Orbital Myositis in Behçet's Disease: A Case Report with MRI Findings
}

\author{
Jee-Hoon Roh Seong-Beom Koh Ji Hyun Kim \\ Department of Neurology, Guro Hospital, Korea University School of Medicine, Seoul, Republic of Korea
}

Dear Sir,

Behçet's disease (BD) is a chronic, relapsing systemic vasculitis of unknown etiology characterized by variable systemic manifestations involving the skin, eye, lung, intestine, joint and nervous system [1]. Among these, muscular involvement is rarely reported and ocular muscle involvement is more limited $[2,3]$. We describe here the case of MRI-documented orbital myositis in a patient with BD who presented with relapsing orbital pain, emphasizing the importance of $\mathrm{BD}$ in the differential diagnosis of orbital myositis.

\section{Case Report}

A 63-year-old woman with a history of BD was seen in our clinic because of an 8month history of chronic progressive right orbital pain that had occurred since December 2004. The severe lancinating pain was confined to the right orbit, tending to be aggravated with eyeball movements. She had experienced two episodes of right orbital pain of several weeks' duration in 1992 and 1995, resulting in spontaneous recovery. Previously, she had been diagnosed as having BD on the convergence of recurrent oral ulcerations, uveitis, erythema nodosum and a positive pathergy test [4]. She remained on colchicine $1.2 \mathrm{mg} /$ day and had been asymptomatic since 2001. She denied a history of hypertension, diabetes, migraine, malignancy, asthma or hyperthyroidism. On examination, the pupils reacted normally to light and were of equal size. Visual acuity was 20/20 in each eye. Mild proptosis without ptosis was observed on the right. No limitation was found in 6 cardinal extraocular movements without diplopia in any direction. Neither papilledema nor raised intraocular pressure was found on ophthalmological examination. The remaining neurological examination was normal. Examination for HLA-B5 and -B51 was positive. Laboratory works including complete blood count, muscle enzymes, sedimentation rate, C-reactive protein, rheumatoid factor, antinuclear antibodies, antineutrophil cytoplasmic antibodies, angiotensinconverting enzyme, thyroid function test and antithyroid antibodies were all within normal ranges. MRI of the orbit demonstrated fusiform enlargement of the right medial rectus muscle with strong enhancement (fig. 1a, c). Cerebrospinal fluid (CSF) examination was unrevealing. Cytological CSF examination showed no malignant cells. Subsequent CSF tests for viruses, fungi and parasites were all negative. A careful search for occult malignancy was made using serum tumor markers, gastrointestinal endoscopies, chest radiography, abdominal CT and gynecological evaluation, yielding negative results. Finally she was diagnosed as suffering from orbital myositis associated with BD. She was then started on intravenous methylprednisolone ( $1 \mathrm{~g} /$ day for 5 days) with prompt and dramatic responses, followed by oral pred- nisolone $50 \mathrm{mg} /$ day. Six months later, she has remained on oral prednisolone $30 \mathrm{mg} /$ day without recurrence. Repeat MRI performed 3 months after the first MRI examination revealed marked improvement of the medial rectus swelling and resolution of the right proptosis (fig. $1 b, d$ ).

\section{Discussion}

Our patient presented with chronic relapsing orbital pain, and MRI revealed enlargement of the medial rectus with strong enhancement, clinically and radiologically consistent with orbital myositis. Orbital myositis refers to nonspecific orbital inflammation that involves exclusively the extraocular muscles, presenting with exceedingly painful ophthalmoplegia, ptosis or proptosis. The conditions known to be associated with orbital myositis included infections (e.g. Lyme disease and trichinosis), Graves' disease, sarcoidosis, Crohn's disease, systemic lupus erythematosus, polyarteritis nodosa, rheumatoid arthritis, Wegener's granulomatosis and neoplastic processes [2, 5-9]. Diagnosis is usually based on clinical and radiological grounds; however, histological confirmation is mandatory especially to exclude infectious and systemic diseases with clinical similarities. We therefore perform a thorough evaluation to exclude these possible associations, leading to a diagnosis of orbital myositis associated with BD. Despite the unilateral lesion, fusiform en-

\section{KARGER}

Fax +4161306 1234 E-Mail karger@karger.ch www.karger.com
(C) 2006 S. Karger AG, Base 0014-3022/06/0561-0044\$23.50/0

Accessible online at: www.karger.com/ene
Ji Hyun Kim, MD, Assistant Professor

Department of Neurology, Guro Hospital, Korea University School of Medicine 80 Guro-Dong, Guro-Ku

Seoul 152-703 (Republic of Korea)

Tel. +82 2818 6940, Fax +82 2818 6943, E-Mail jhkim.merrf@gmail.com 
Fig. 1. Gadolinium-enhanced, fat-suppressed $T_{1}$-weighted axial (a) and coronal (c) MR images at the point of severe right ocular pain demonstrating slight proptosis of the right eye and fusiform enlargement of the right medial rectus muscle with strong enhancement (white arrowheads). Gadolinium-enhanced, fat-suppressed $\mathrm{T}_{1}$-weighted axial (b) and coronal (d) MR images obtained 3 months later showing complete resolution of the right medial rectus swelling (white arrowheads) with disappearance of proptosis.
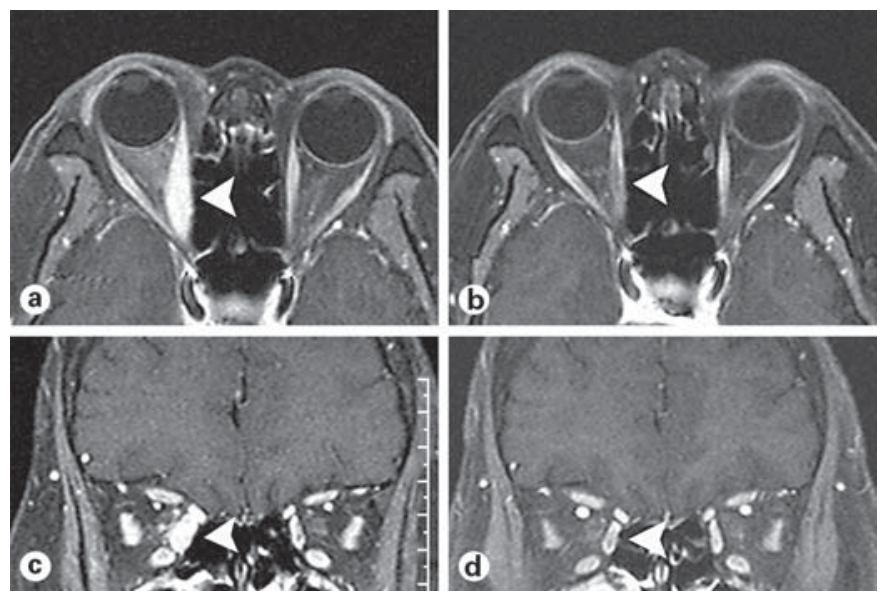

largement of the extraocular muscle sparing the tendons, as shown in our patient, is typical of Graves' ophthalmopathy. However, our patient had no history of Graves' disease and laboratory parameters to test for Graves' disease were all negative, excluding this possibility. The finding of clinical recovery along with resolution of the MRI abnormality following shortterm corticosteroid therapy further supported our diagnosis. Although histological confirmation was not performed in our patient, the chronicity of the disease over 13 years with multiple relapses and remissions is hardly expected in the neoplastic conditions.

Muscular involvement in $\mathrm{BD}$ is rare and usually manifested by localized as well as generalized myositis of skeletal muscles presenting with myalgia or muscle weakness [10-14]. MRI features included focal enlarged muscular lesions showing increased $\mathrm{T}_{2^{-}}$and decreased $\mathrm{T}_{1}$-weighted signals with contrast enhancement [13, 14]. Histological features comprised a chronic inflammatory cell infiltrate, muscle fiber degeneration and perivascular infiltration [10-12]. There are few reports showing a likely association between orbital myositis and BD $[2,3]$. To our knowledge, this is the first report of MRI-presented orbital myositis in BD. Corticoste- roid therapy produces dramatic responses, but recurrences and relapses are common when the therapy is discontinued. The prognosis is favorable in general with frequent spontaneous resolution.

Chronic orbital myositis poses diagnostic and therapeutic challenges. MRI assists in confirming the diagnosis and may help avoid histological examination in the proper clinical setting. Although rare, $\mathrm{BD}$ should be included in the differential diagnosis of chronic relapsing orbital myositis.

\section{References}

1 Lannuzel A, Lamaury I, Charpentier D, Caparros-Lefebvre D: Neurological manifestations of Behçet's disease in a Caribbean population: clinical and imaging findings. J Neurol 2002;249:410-418.

2 Garrity JA, Coleman AW, Matteson EL, Eggenberger ER, Waitzman DM: Treatment of recalcitrant idiopathic orbital inflammation (chronic orbital myositis) with infliximab. Am J Ophthalmol 2004;138:925-930.

3 Dursun D, Akova Y, Yucel E: Myositis and scleritis associated with Behçet's disease: an atypical presentation. Ocul Immunol Inflamm 2004;12:329-332.

4 Criteria for diagnosis of Behçet's disease: International Study Group for Behçet's Disease. Lancet 1990;335:1078-1080.

5 Bullen CL, Younge BR: Chronic orbital myositis. Arch Ophthalmol 1982;100:1749-1751.
6 Selva D, Dolman PJ, Rootman J: Orbital granulomatous giant cell myositis: a case report and review. Clin Exp Ophthalmol 2000; 28:65-68.

7 Thorne JE, Volpe NJ, Wulc AE, Galetta SL: Caught by a masquerade: sclerosing orbital inflammation. Surv Ophthalmol 2002;47: 50-54.

8 Mahr MA, Salomao DR, Garrity JA: Inflammatory orbital pseudotumor with extension beyond the orbit. Am J Ophthalmol 2004; 138:396-400

9 Capone A Jr, Slamovits TL: Discrete metastasis of solid tumors to extraocular muscles. Arch Ophthalmol 1990;108:237-243.

10 Arkin CR, Rothschild BM, Florendo NT, Popoff N: Behçet syndrome with myositis: a case report with pathologic findings. Arthritis Rheum 1980;23:600-604.

11 Yazici H, Tuzuner N, Tuzun Y, Yurdakul S: Localized myositis in Behçet's disease. Arthritis Rheum 1981;24:636.

12 Worthmann F, Bruns J, Turker T, Gosztonyi G: Muscular involvement in Behçet's disease: case report and review of the literature. Neuromuscul Disord 1996;6:247-253.

13 Sarui H, Maruyama T, Ito I, Yamakita N, Takeda N, Nose M, Yasuda K: Necrotising myositis in Behçet's disease: characteristic features on magnetic resonance imaging and a review of the literature. Ann Rheum Dis 2002;61:751-752.

14 Akansel G, Akgoz Y, Ciftci E, Arslan A, Demirci A: MRI findings of myositis in Behçet disease. Skeletal Radiol 2004;33:426428. 